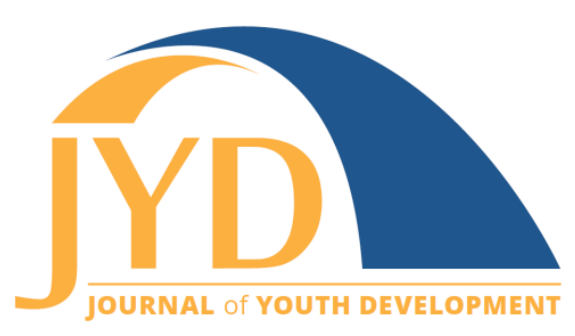

http://jyd.pitt.edu/ | Vol. 16 Issue 1 DOI 10.5195/jyd.2021.1001 | ISSN 2325-4017 (online)

\title{
Motivation (Constructs) Made Simpler: Adapting Self-Determination Theory for Community-Based Youth Development Programs
}

\author{
Denise Jones \\ University of Michigan \\ jonesdee@umich.edu \\ Paul Feigenbaum \\ Florida International University \\ pfeigenb@fiu.edu \\ Dennis F. Jones \\ West Virginia University \\ floyd.jones@mail.wvu.edu
}

\begin{abstract}
Motivation is a key factor for enhancing psychological engagement among underserved youth. However, the abundance of motivational constructs complicates the translation of theory into practice by community-based youth development programs. This paper simplifies the translation process, presenting an actionable motivation model derived from Ryan and Deci's (2000) self-determination theory (SDT) and its sub-construct, organismic integration theory (OIT). This model was developed by Youth Enrichment Services (YES), a Pittsburgh-based nonprofit that cultivates long-term relationships, academic and professional success, and community engagement among low-income, adolescent students of color. Although intrinsic motivation to learn is more positively associated with psychological engagement than extrinsic motivation, contemporary institutions are built around extrinsic incentives. Therefore, guided by OIT, this model cultivates the gradual internalization of motivational regulation by supporting youth's psychological needs of relatedness, competences, and autonomy. As a practical application of selfdetermination theory, this model holds promise for adoption by other youth development programs.
\end{abstract}

Key words: self-determination theory, organismic integration theory, basic psychological needs, extrinsic motivation, intrinsic motivation, underserved youth

(cc) EY New articles in this journal are licensed under a Creative Commons Attribution 4.0 License. This journal is published by the University Library System, University of Pittsburgh and is cosponsored by the University of Pittsburgh Press. The Journal of Youth Development is the official peer-reviewed publication of the National Association of Extension 4-H Youth Development Professionals and the National AfterSchool Association. 


\section{Internalizing Motivation}

\section{Introduction}

Over the past several decades, multiple constructs that connect human motivation to academic achievement and youth development have been proposed (Murphy \& Alexander, 2000). Among these motivation constructs are expectancy-value theory (Safavian, 2019; Wigfield \& Eccles, 2000), achievement goal theory (Ames, 1992; Newton et al., 2006; Pintrich, 2000), self-efficacy (Schunk, 1991; Zimmerman, 2000), and self-determination theory (Deci et al., 1991; Reeve et al., 2008). The abundance and theoretical complexity of motivation constructs, many of which employ similar or overlapping terminology, can cause confusion when seeking to translate theory into practice and when evaluating motivation-focused interventions (Murphy \& Alexander, 2000). Schunk (2000) emphasizes that while lack of agreement on motivation constructs is "understandable," it is nevertheless "problematic, especially for newcomers to the field, practitioners, students, and those of us who attempt to make sense of motivation" ( $p$. 116). Schunk notes further that motivation studies often rely on brief timespans of days or weeks, whereas motivation to achieve challenging goals must be maintained for months or years.

The implications of how motivation supports academic achievement and development over long periods are especially significant for underserved youth of color, many of whom experience reduced mental bandwidth related to chronic poverty (Evans, 2004; Mullainathan \& Shafir, 2014) and systemically unequal access to health care, nutrition, recreation, and food security (Heckman, 2007). Many of these youth also suffer from untreated adverse childhood experiences (ACE) that include sexual and/or physical abuse, homelessness, and family incarceration (Hughes et al., 2017). Chronic adversity taxes children's bodies and brains (Sapolsky, 1994) in ways that are not compatible with engaged learning (Tough, 2012). Because high academic motivation is associated with successful academic behaviors such as self-regulation (Reeve et al., 2008; Zimmerman \& Schunk, 2008) and persistence at mastering complex, challenging tasks (Reeve et al., 2008), enhancing academic motivation among underserved students can potentially mitigate against some of the harmful consequences of systemic inequity (Tough, 2016). However, because these inequities cause physiological and psychological harm at early ages, and because the consequences of this harm build over time (Heckman, 2007), it is perhaps unreasonable to expect relatively short-term interventions to have long-term impacts on academic motivation and achievement.

This paper seeks to address both the challenge of translating abstract motivational constructs into effective models of practice, and of cultivating academic motivation and persistence among 


\section{Internalizing Motivation}

underserved students over extended periods of time. Specifically, we conceptualize and present a case study of a motivation-enhancement model inspired by Ryan and Deci's (2000) selfdetermination theory (SDT) and its sub-construct, organismic integration theory (OIT). Selfdetermination theory represents a framework for human motivation based on the idea that when people's innate psychological needs of relatedness, autonomy, and competence are nurtured, their self-motivation to explore, to challenge themselves, and to master new skills can be optimized. When applied to education, SDT focuses on enhancing student interest in learning and confidence in their capacity to succeed (Deci et al., 1991). We propose that this construct and its sub-construct OIT, by conceptualizing a motivation continuum that ranges from externally to internally regulated motivation, hold promise for simplifying the translation of theory into practice amid highly dynamic community-based settings such as Youth Enrichment Services (YES), a 501(c)(3) that is the focus of our case study. YES administers year-round youth development programs for underserved, adolescent students of color in northeast Pittsburgh. The nonprofit builds long-term, multi-year relationships with students that often begin in middle school and extend into college. YES's motivational model represents a practiceoriented application of self-determination theory that we believe can be adopted and further adapted by community-based youth development programs that similarly maintain long-term relationships with adolescent-aged students.

\section{Self-Determination Theory, Intrinsic Motivation, and Extrinsic Motivation}

According to Ryan and Deci (2000), self-determined behaviors that lead to enhanced interest, performance, and resilience in learning emerge from satisfying three basic psychological needs: autonomy, competence, and relatedness. Autonomy reflects the need to feel one has volition over which tasks and activities to pursue and how to pursue them; competence reflects the need to feel that one is doing well at a given task or activity, and relatedness reflects the need to feel a sense of connectedness to others. Enhancing self-determination has been shown to have salutary effects on youth engagement in school and other domains (Larson \& Rusk, 2011; Reeve et al., 2008; Zimmerman \& Schunk, 2008).

Self-determination theory is often associated with intrinsic motivation (Ryan \& Deci, 2000), which reflects the inherent satisfaction of learning without the expectation of receiving tangible rewards; by contrast, extrinsic motivation involves performing activities with the desire or expectation of obtaining concrete outcomes such as trophies, medals, high test scores, etc. Research on motivation consistently shows that people work harder, think more creatively, and 


\section{Internalizing Motivation}

demonstrate greater persistence when motivated by inherent enjoyment and interest rather than by the pursuit of rewards (Larson \& Rusk 2011; Ryan \& Deci, 2000; Schwartz, 2015). Nevertheless, contemporary societal institutions such as formal education (Tough, 2016), as well as most workplaces (Schwartz, 2015), are structured around extrinsic incentives, including both shorter-term goals such as obtaining a high grade on a course assignment or exam, and longer-term goals such as procuring a prestigious career and financial security. Furthermore, even when freely chosen, much learning requires pursuing tasks that are monotonous, repetitive, and that people do not find intrinsically motivating (Ryan \& Deci, 2000; Yeager, Henderson, et al., 2014). Invariably, young people will spend significant percentages of their lives studying and working within systems that prioritize the acquisition of rewards and/or the prevention of punishments.

\section{Organismic Integration Theory: Internalizing Extrinsic Motivation}

Although Ryan and Deci (2000, p. 70) affirm that perhaps "no single phenomenon reflects the positive potential of human nature as much as intrinsic motivation," they propose that motivation reflects a continuum, rather than a rigid binary, of extrinsic and intrinsic factors. According to their organismic integration theory (OIT) - a sub-construct of SDT-there are various types of extrinsic motivation whose regulation ranges from relatively external, thus emanating from outside the self, to internal, thus integrated into the self. Behaviors performed in compliance to authority, to obtain a contingent reward, or to avoid a contingent punishment, are externally regulated, which is most consistent with the carrots-and-sticks approach of operant behaviorism (Skinner, 1953), as well as with the high-stakes standardized testing and zero-tolerance discipline policies that prevail in many urban schools (Schwartz, 2015). Whereas introjection, which Ryan and Deci (2000) define as "somewhat external" (p. 72), is associated with impressing people whose social approval one deems important. Introjected regulation corresponds with Dweck's (1999) concept of performance goals, which people pursue to demonstrate their accomplishments to others. Ryan and Deci (2000) define the next type, identification, as "somewhat internal" (p. 72), because it reflects a "conscious valuing of a behavioral goal or regulation, such that the action is accepted or owned as personally important" (p. 72). Whereas the final regulation, integration, indicates that one has fully internalized one's goals. Crucially, the human capacity to progress along the motivation continuum demonstrates that "individuals can be extrinsically motivated and still be committed and authentic" (p. 74). 


\section{Internalizing Motivation}

Ryan and Deci (2000) emphasize that moving through the stages of internalized motivational regulation can be facilitated by environmental factors that support the psychological needs of relatedness, competence, and autonomy. Relatedness is particularly central to this process, in that students often initiate non-intrinsically interesting behaviors because they seek the approval of someone who values these behaviors. Internalization might be further realized as students see themselves becoming increasingly competent at a task, especially one that is socially valued. And autonomy supports internalization when students find the behavior personally meaningful. However, Ryan and Deci stipulate that moving through the stages of internalized motivational regulation can be a slow, non-linear, and highly context-dependent process.

With many schools failing to nurture self-determination (Tough, 2016), community-based youth development programs can support youth success in school and other domains by helping them navigate the process of motivational internalization. Accordingly, some after-school programs (Berry \& LaVelle, 2013; Grolnick et al., 2007), recreation camps (Hill \& Sibthorp, 2006), youth activism programs (Dawes \& Larson, 2011), youth enrichment programs (Martin, 2005), and circus arts programs (Agans et al., 2019) have explicitly emphasized SDT as a motivational construct. Dawes and Larson's (2011) study of diverse youth programs indicates that even if youth are extrinsically motivated to participate at the start, it is possible to enhance their psychological engagement through their experiences in the program. Berry and LaVelle (2013) emphasize that practices such as establishing strong relationships with adult staff, cultivating ability through extracurricular activities, and giving students choice over what activities to pursue-i.e., satisfying the basic psychological needs of relatedness, competence, and autonomy-can enhance engagement among students who initially join after-school programs for extrinsically motivated reasons. Duerden and Gillard (2008) indicate that positive youthadult relationships support autonomy, relatedness, and competence, which in turn provides scaffolding for youth to navigate the challenges of adolescence. Akiva and colleagues (2014) affirm that involving adolescent youth in decision-making processes can enhance their motivation to participate in development programs.

Some of these programs, however, focus specifically on enhancing intrinsic motivation rather than by internalizing externally regulated motivation (Agans et al., 2019). Also, whether focused on school- or community-based settings, many studies of self-determination use single-point-intime measurements (Agans et al., 2019; Standage et al., 2006; van Egmond et al., 2020). Dawes and Larson (2011) emphasize the need for more research on the processes by which 


\section{Internalizing Motivation}

motivation changes over time so that youth become more psychologically engaged in development programs. This is particularly important for underserved youth, who are far less likely than their more privileged peers to experience environments where their basic psychological needs are met consistently (Heckman, 2007; Tough, 2016), and who in many cases are assigned to-rather than self-joining-youth development programs, which they perceive as a form of remediation or punishment (Jones, 2017). Both recruiting students to attend after-school programs and keeping them engaged over time are ongoing challenges for many practitioners (Akiva \& Horner, 2016; Berry \& LaVelle, 2013); these problems are exacerbated for underserved youth who frequently face competing demands from family or jobs and who may experience transportation challenges. In general, more work must be done to create and refine actionable youth development models that longitudinally guide underserved youth through processes of motivational internalization. In the next section, we explore one such model established by the nonprofit Youth Enrichment Services (YES).

\section{Coming Because They Need To, Staying Because They Want To: The Motivational Model at Youth Enrichment Services}

Established as a 501(c)(3) in 1994, Youth Enrichment Services' mission is "to create hope out of hopelessness, to paint a bright future out of uncertainty, and to give young people from . . . urban communities a portrait of themselves as successful, empowered, and confident leaders" (YES, n.d.). Toward this end, YES utilizes various programs to facilitate academic and professional success, leadership, and civic development among low-income, primarily African American youth ranging from 10 to 21 years old in the northeast Pittsburgh community of East Liberty. At its inception, YES was an academic enrichment program designed to counter summer learning loss (Jones \& Jones, 2020), a problem that disproportionately affects lowincome students of color (Alexander et al, 2007; Blazer, 2011). Over time, YES has developed year-round programming that includes an amalgamation of youth employment, cultural enrichment, and civic engagement opportunities (Jones, 2017). In recent years, YES projects have included a citizen science and advocacy initiative regarding lead contamination in Pittsburgh neighborhoods (Daly, 2017; Holsopple, 2017; Jones et al., 2020;) and a college prep program (Jones \& Jones, 2021).

Students come to YES through one of two umbrella programs: Diversion 2000, which offers juvenile offenders an alternative to detention, and Mentoring Partnerships, which offers employment opportunities connected to professional and life-skills development, academic 


\section{Internalizing Motivation}

enrichment, and community engagement. In both cases, students join YES for extrinsically regulated reasons, which makes sense considering how many have endured chronic financial struggles and years of institutionalization within a system that emphasizes grades and test scores and that often criminalizes minority youth rather than supporting their mental and physical wellbeing (Noguera, 2008). YES recognizes that students come because they need to, but the goal is for them to stay because they want to (Jones, 2017).

\section{Figure 1. The YES Motivational Model}

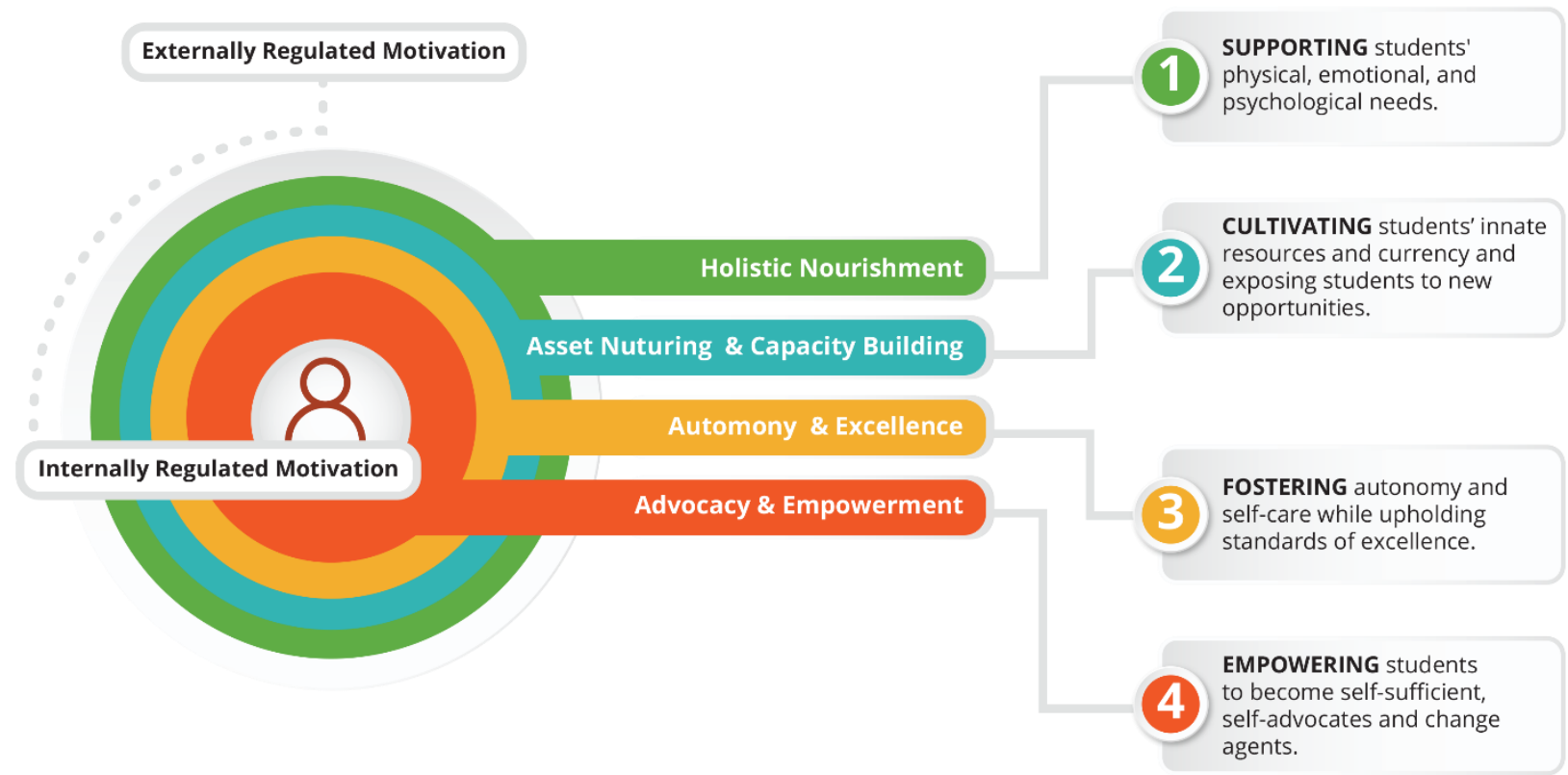

As illustrated in Figure 1, YES's model depicts four concentric circles that symbolize the internalization of motivational regulation. Like the continuum proposed by Ryan and Deci's (2000) organismic integration theory, each inner circle reflects greater internalization. Furthermore, each of the outer three circles spotlights one of the three basic psychological needs associated with self-determination. The outermost circle highlights relatedness, which Ryan and Deci cite as "centrally important for internalization" (p. 73). That is, extrinsically motivated behaviors are not interesting in and of themselves, and students are more likely to pursue them at first if these behaviors are valued by other people-in the case of YES, peers or adult staff-whose esteem the students themselves value. The second circle highlights competence, in that people become more motivated to pursue activities such as mastering a new skill as they see themselves improving at that activity. The third circle highlights autonomy. As Ryan and Deci (2000) indicate, environments that support relatedness and competence can 


\section{Internalizing Motivation}

enable partial internalization of extrinsically motivated behaviors, but environments cannot cultivate full internalization unless they are also autonomy supportive. Ryan and Deci also emphasize the interrelatedness of needs, and we want to stress that although each of the three outer circles spotlights one need-in part to support the clarity and simplicity of the model-the concentricity of circles reflects that all three needs are relevant to all YES programming.

Furthermore, while not explicitly based on Lave and Wenger's (1991) concept of legitimate peripheral participation, the presence of both an outermost and an innermost circle follows a similar logic to Lave and Wenger's model, whereby "newcomers" on the periphery of a community of practice gradually become "oldtimers" who move inward to the core as their participation and investment grow over time. As per OIT (Ryan \& Deci, 2000), however, moving toward the inner circles can be a non-linear process. In some cases, proceeding to the core might take place over several years as initially skeptical or uncertain youth participants gradually connect with the organization's mission and desire to contribute further. Other students might come to the organization already highly motivated to participate, perhaps because they were eagerly referred there by a peer or because they have previously established long-term academic, professional, and/or civic goals, and they believe the organization can help them achieve these goals; such students begin already situated at one of the inner circles. The concentricity of circles indicates that students need not follow a sequential pathway to the core, though in practice, beginning at the outermost circle and gradually working inward over multiple years is the likeliest scenario for the majority. Some students, of course, never reach the innermost circle. But as an embedded presence in the community, YES provides the opportunity for students to engage, disengage, and re-engage at various times. In the following sections, we examine how the outer circles help cultivate participants' internalized regulation of academic, professional, and civic goals.

\section{The Outer Circle: Building Connectedness and Trust Through Holistic Nourishment}

The outermost circle of YES' mentorship model emphasizes relatedness through metaphors of nourishment and family. Many YES students experience chronic food insecurity that contributes to a culture of unhealthy eating. In an enforced hunter-gatherer mentality, students eat what is available in the moment-frequently unhealthy snacks and drinks-because they do not always know when they will luck into another opportunity to eat. Food insecurity is associated with reduced mental bandwidth for concentrating on academic tasks and thinking beyond one's immediate needs (David, 2017; Tough, 2016), whereas being well-fed increases one's ability to engage. Food, with a special emphasis on healthy eating, is almost always present at YES 


\section{Internalizing Motivation}

events and meetings, which also cultivate a family atmosphere (Jones \& Jones, 2020). When students are among peers and staff, and when they do not have to worry about food, their mental bandwidth and their sense of relatedness are both enhanced, which fosters program "buy-in."

Cultivating belongingness and trust among students who have good reason to mistrust their elders or the larger system (Yeager, Purdie-Vaughns, et al., 2014) is not an efficient process that can be streamlined into codified beginning and ending dates. Building these emotional foundations for engagement can take years, and it often means continually inviting participation from students who are disaffected and/or inconsistently meeting obligations. This practice exemplifies psychologist Carl Rogers's (1957) unconditional positive regard(UPR), which reflects the idea that no matter how a person behaves, "you respect the person as a human being with agency to choose how to respond to their situation, and that no matter how dangerous or dysfunctional they seem to be, they are doing their best" (Joseph, 2012, para. 4). Practicing UPR does not mean failing to hold people accountable; it means recognizing their humanity and preserving the belief that they have agency to improve their lot no matter how trying their circumstances.

Surveys and interviews indicate YES students' overwhelming appreciation of the relationships they build with staff and peers. Students frequently invoke the language of family with statements such as, "I keep coming back because, to me, we're all like one big family" (Jones \& Jones, 2020, p. 64). Another student who served as a peer mentor for over 3 years similarly observed that "I feel like not only did I make friends, but I made family. [YES] became a family thing" (Jones \& Jones, 2020, p. 64). This response suggests that YES' family-like environment elicited a level of comfort and self-efficacy that sustained the student's investment in the program. Another 3-year participant explained,

YES [is] basically home and everyone's just family around here. Everyone knows the number one thing with me, as far as I'm concerned in my life, is family. And because I consider YES my family . . . It just seemed normal for me to come back every summer. (Jones \& Jones, 2020, p. 64)

In addition to the family-like atmosphere, youth emphasize the belongingness they feel among program peers, as demonstrated in the following statement: "[YES] felt like a place where I kind of, I guess, fit in . . . so, I wanted to come back to be with my peers" (Jones, 2017, pg. 21). As students' qualitative responses highlight, YES is an environment that nurtures their 


\section{Internalizing Motivation}

needs for belongingness, family, and peer support. YES is, in effect, a place of sanctuary (Akiva et al., 2017), or a safe and affirming space for youth to dwell with peers and adult staff.

YES students meet peers with similar life goals, and they come to recognize the value of their peers' educational success as it relates to their own pursuits. In a survey addressing students' reasons for participating in YES, more than 70 percent of respondents referenced peer interaction and relationship building as important factors in shaping their YES experiences and future educational trajectories (Jones, 2017). One student explained that "having [peers] who share a drive towards educational success imparts a unique influence on YES participants like myself" (Jones, 2017, p. 20).

\section{The Second Circle: Asset Nurturing and Capacity Building}

The second circle highlights competence. YES actualizes this need through summer work opportunities, via which students enhance assets they already possess and cultivate new ones as they explore personal interests and potential careers, and as they learn about work culture. Beyond financial considerations, competence accrues to students through their enhanced sense of currency among peers and family members, not only because they earn an income, but also because they take on leadership roles as their confidence and investment in the program grow. In a money-oriented society that associates dignity with gainful employment (Thompson, 2015), earning income is an important way for students to perceive their own value-to themselves, their families, and the broader society. Early work experiences also play a key role in healthy youth development (Sum et al., 2014). These experiences allow youth to create professional networks, develop a mix of skills, and build their financial capacity.

YES is a service provider for Partner4Work, a Pittsburgh-based workforce development organization that runs the Learn \& Earn Summer Youth Employment Program. Through Learn \& Earn, underserved youth from ages 14 to 21 work in summer positions around the city of Pittsburgh (Partner4Work, n.d.). Learn \& Earn students work in diverse jobs and occupational areas to acquire professional experience, technical skills, and knowledge of employer expectations, as well as exposure to possible career paths. Through this partnership, YES has developed summer programing that integrates leadership development, employment preparation, and academic enrichment to prepare youth not only for future jobs but also to stimulate their academic interests and to deepen their commitment to peers. 


\section{Internalizing Motivation}

Under the umbrella of Learn \& Earn, YES's Summer Work for Success (SWFS) program enhances professional skills for students-who are called summer scholars-through various workshops and activities. SWFS sessions enable students to explore careers, develop interpersonal skills-including responsibility, sociability, and self-management-and to discuss ethics, decision-making, and workplace etiquette. SWFS' auxiliary goals include providing summer scholars with an understanding of work documentation, synthesizing their current experiences for résumés and cover letters, and navigating job applications and interview processes. Summer scholars are then placed in apprenticeship positions at the YES office.

Older students are placed at diverse worksites to augment their employability preparation. These sites are secured through existing YES partnerships with organizations such as the Allegheny County Health Department; Carnegie Mellon University; and local companies, nonprofits, and schools. Advanced summer scholars spend 3 to 5 days each week at their individual work sites practicing myriad job responsibilities. Students are monitored by adult supervisors and are expected to fulfill their contractual work obligations, and in some cases, they experience agentic adult partnerships where they are empowered to define their own work alongside adults (Akiva \& Petrokubi, 2016). In Summer 2018, students maintained a 90\% employment completion rate (Jones \& Jones, 2018, p. 40). And in performance evaluations by onsite supervisors, $86 \%$ of supervisors "noted that youth are productive and helpful in conducting daily workplace activities and are valuable assets to their organizations" (Jones \& Jones, 2018, p. 42).

\section{The Third Circle: Autonomy, Excellence, and Ownership}

The third circle highlights autonomy, which YES cultivates by giving students' considerable leeway to choose personally meaningful intellectual projects as they discover, research, analyze, and propose solutions to real problems in their communities. Specifically, the Summer Study for Success (SSFS) program exposes students to research and career exploration alongside practitioners and experts in a revolving array of fields that include sport science and health, business and entrepreneurship, African American studies, and culinary arts and nutrition (Jones \& Jones, 2018). SSFS also enhances youths' research, critical thinking, writing, and presentation skills. This process includes an empirical research project via which students identify a local problem, formulate a research question and hypothesis, create and administer surveys of local residents, analyze and draw conclusions from the data, and then report findings to community stakeholders through poster presentations at an annual YES Symposium. One student commented on the importance of autonomy in selecting her project: 


\section{Internalizing Motivation}

I got to determine what I wanted to explore and focus on, choose a topic of interest, a class I wanted to take, and focus on and learn about that topic . . . and I think it's really important that I get to adapt my own ideas, build my own knowledge, and shift my own opinions about the world (Jones, 2017, p. 25).

\section{The Fourth, or Innermost, Circle: Advocacy and Empowerment}

Reflecting the full integration of academic and professional motivation into the self, the innermost circle represents students' transformation into mentors and community advocates. In recent years, for instance, advanced summer scholars worked with University of Pittsburgh and Allegheny County Health Department health professionals to study the historical and scientific implications of lead exposure's impact on minority and poor communities such as LincolnLemington (Daly, 2017; Holsopple, 2017; Jones et al., 2020). A primary goal of this project was to utilize youth as mediators to restore broken trust between local Pittsburgh residents and government institutions like the health department.

As members of the local community, YES students had built-in trust among residents, who welcomed students into their homes in ways that would not have been possible for government officials. Students practiced community-based research that included gathering data, interviewing residents, facilitating conversations between parents and children, and conducting community asset-mapping (Jones et al., 2020). Students also organized neighborhood meetings and worked with the health department to make resources more relevant and accessible for families.

Collectively, students spent over 300 hours in the community, surveyed over 30 families, and increased residents' use of social media as a platform for community events and health awareness (Poindexter, 2017). Furthermore, positive relationships were forged between youth, community members, and the health department. In a Pittsburgh Post-Gazette article about the lead project, health department Director Karen Hacker emphasized the key role of student advocacy, explaining that "We really need [students] to get messages out there" (Daly, 2017, p. C-1). The president of Lincoln-Lemington Community Consensus Group (LLCCG) also touted the students' contributions at a 2017 community health awareness session:

We, LLCCG, strive to keep residents at the center of our work, however, given our limited capacity, we are often unable to engage authentically and meaningfully with every community member. Having YES youth fill this void and prioritize our community was both timely and appreciated. From the moment 


\section{Internalizing Motivation}

[YES] presented at our Saturday meeting, we knew we were blessed to have support and that they would make a positive impact in our neighborhood. (Ferguson, 2017)

Students' own reflections mirror the aforementioned ones. In a presentation at the 2019 Conference on College Composition and Communication, one participant remarked: The lead project was one of my best and most memorable YES experiences. At the time, I did not understand the true value of engaging residents in a survey on lead exposure, but since the program has end[ed], I have referenced this work more than a dozen times, utilized the skills I have gained from developing research protocol and analyzing data in high school, submitted my research presentations as supplemental data for my college applications, and remained active in my community. (Reed, 2019)

Students seeing themselves as stakeholders entrusted with maintaining their community's health demonstrates how extensively they have internalized the civic motivation to effect social change.

\section{Limitations}

Students' robust participation in YES programs, their evolution toward positions of leadership, and reports from surveys and interviews indicate that motivation for academic achievement, professional development, and civic engagement become increasingly internalized the longer students participate. However, there are challenges and limitations in measuring the internalization of motivation vis-à-vis OIT. For example, devices for measuring motivation tend to focus directly on intrinsic motivation (Ryan, 1982; Ryan et al., 1990). Fortunately, because the psychological needs of autonomy, relevance, and competence are germane to both intrinsic motivation and the internalization of extrinsic motivation, it is possible that measurement devices could be easily adapted. Further research could also explore the stages of internalization in greater depth and examine how closely the engagement of students who have fully integrated extrinsic motivation compares with that of students who were intrinsically motivated from the beginning of their participation.

Other limitations reflect the fact that measurements of motivation often focus on randomized groups performing discrete tasks in laboratory-based experiments (Deci et al., 1994; Ryan, 1982; Ryan et al., 1990). Studying motivation in less-controlled environments such 


\section{Internalizing Motivation}

as schools and youth-development programs is far more challenging, because of the many confounding and interconnected variables in play (Berry \& LaVelle, 2013; Maehr \& Midgley, 1991; Morton \& Montgomery, 2013). This is especially true of an organization like YES, which at any given time has dozens of youth participating simultaneously in multiple programs. Furthermore, while studies limited to non-randomized groups are valuable, they are also possibly unrealistic in this area, where youth are either required, or they self-select, to participate. Traditional metrics of motivation may have limited usefulness for community-based programs that are, by nature, highly personalized and local. Future studies of motivation in community-based youth development projects should seek to establish context-specific longitudinal metrics utilizing methodologies such as grounded theory (Dawes \& Larson, 2011; Larson, 2011), mixed-methods approaches that complement quantitative metrics with qualitative research such as interviews of youth and staff (Akiva \& Horner, 2016), and community-based participatory action research methods (Burns et al., 2011). The development of community-specific motivation measures could have mutual benefits for researchers and community partners. Such tools could help organizations like YES refine their strategies for enhancing motivation among students. Simultaneously, these tools might help researchers better understand how their models translate out of labs and into real-world settings. The more extensively scholars of motivation partner with community-based practitioners-including codesigning and evaluating research protocols-the more impactful their models will likely become over time.

Further potential limitations reflect the inherent challenges of translating abstract and conceptually complicated theoretical frameworks into clear and actionable models for community-based programs that are situated in highly dynamic settings. For example, the spotlight on one basic psychological need for each of the three outer circles reflects the YES model's emphasis on clarity and usability. However, although the visual image of concentric circles-rather than alternate potential designs such as the pyramid in Maslow's (1970) hierarchy of needs model-is meant to demonstrate that relatedness, competence, and autonomy are interconnected, the highlighting of different needs in different circles might unintentionally lead practitioners to perceive a sequential ordering of needs, such that they do not support autonomy and competence until relatedness has been established. Future studies might examine the extent to which practitioners applying the model understand the psychological needs as interconnected and relevant to all stages of motivational internalization. 


\section{Internalizing Motivation}

\section{Implications and Future Directions}

In an ideal world, all youth-and adults, for that matter-would have unlimited opportunities to enhance their knowledge, skills, and abilities in various academic, artistic, and recreational domains for intrinsically motivated reasons. Compared to students who "other-join" organized youth activities for external reasons, students who "self-join" (Berry \& LaVelle, 2013) for intrinsic enjoyment tend to experience more positive socioemotional and developmental benefits (Hansen \& Larson, 2007). However, in contemporary society, opportunities for intrinsically motivated learning are often few, especially for low-income students of color who must navigate systems that prioritize transactional rewards and punishments related to grades, financial incentives, and in too many cases, threats of incarceration. The reality is that many underserved youth show up, at least initially, because they have to rather than because they want to.

Still, underserved youth can become more psychologically engaged and pursue increasingly self-determined behaviors as their motivation to participate becomes internalized over time. In turn, they can become more disposed to stay resilient as they negotiate the psychological and physiological consequences of systemic inequality. Because many schools are poorly afforded to internalize motivation for academic and professional success, there is great potential for community-based organizations, particularly those guided by transformational values of family, unconditional positive regard, and student voice, rather than transactional values of grades and test scores.

While YES's motivation model was designed specifically for working with underserved youth, we believe the model is broadly relevant and can be adapted by programs that work with either underserved and/or more privileged youth. When young people experience environments that nurture their needs for autonomy, competence, and relatedness, their resilience, concentration, confidence, and ability to connect with others grow. But when these basic needs are unmet, youth experience "alienation and ill-being" (Ryan \& Deci, 2000, p. 74). Considering the skyrocketing levels of anxiety and stress among youth nationwide (Schrobsdorff, 2016), it seems clear that alienation and ill-being are all too common experiences regardless of students' demographic backgrounds. Helping students internalize extrinsic motivation to establish and achieve long-term academic and professional goals represents one important way to fight this alarming societal trend. Future research might apply the YES model to community-based organizations in various socioeconomic settings in order to assess its potential for replication outside the context of the model's origin. Future studies might also obtain student feedback on 


\section{Internalizing Motivation}

the extent to which they see the model applying to their lived experiences; this feedback could further inform localized adaptation and refinement of the model. Furthermore, because the model's innermost circle emphasizes student leadership in community advocacy, future studies might examine the extent to which motivation to succeed academically and professionally reciprocates with motivation to pursue social justice (Akiva et al., 2017).

And while the YES model intentionally focused on one motivational construct-selfdetermination theory-to simplify translation of theory into practice, future research might adapt the model's conceptual frame in accord with other motivational constructs, such as achievement goal theory (Pintrich, 2000), expectancy-value theory (Wigfield, 1994), attribution theory (Weiner, 1985), or self-efficacy (Bandura, 1991), depending on localized variables, needs, and program goals. Among these constructs, expectancy-value theory may hold particular promise because it employs conceptual terms that fit well with Ryan and Deci's (2000) framework. Like Ryan and Deci, Wigfield and Eccles (2000) emphasize intrinsic value, or the enjoyment one experiences from doing the activity; Wigfield and Eccles further note that utility value, which is how much an activity connects to an individual's future plans, and cost, or the extent to which pursuing one activity limits opportunities to pursue other activities, are conceptually consistent with extrinsic motivation. Finally, because organizations like YES also seek to address basic physical needs such as food security, we suggest further research exploring the overlaps between satisfying youth's physical and psychological needs (van Egmond et al., 2020).

\section{Acknowledgements}

The authors wish to thank those who have given sweat equity, time, and financial resources to support the work and mission of YES. We especially wish to thank the students whose stories, voices, and outcomes continue to inform the work in which YES engages.

\section{References}

Agans, J. P, Davis, J. L., Vazou, S., \& Jarus, T. (2019). Self-determination through circus arts: Exploring youth development in a novel activity context. Journal of Youth Development, 14(3), 110-129. https://doi.org/10.5195/jyd.2019.662 
Journal of Youth Development ｜ http://jyd.pitt.edu/ | Vol. 16 Issue 1 DOI 10.5195/jyd.2021.1001

Internalizing Motivation

Akiva, T., Carey, R., Cross, A. B., Delale-O'Connor, L., \& Brown, M. (2017). Reasons youth engage in activism programs: Social justice or sanctuary? Journal of Applied Developmental Psychology, 53, 20-30. https://doi.org/10.1016/j.appdev.2017.08.005

Akiva, T., Cortina, K. S., \& Smith, C. (2014). Involving youth in program decision-making: How common and what might it do for youth? Journal of Youth Adolescence, 43, 1844-1860. https://doi.org/10.1007/s10964-014-0183-y

Akiva, T., \& Horner, C. G. (2016). Adolescent motivation to attend youth programs: A mixed-methods investigation. Applied Developmental Sciences, 20(4), 278-293. https://doi.org/10.1080/10888691.2015.1127162

Akiva, T., \& Petrokubi, J. (2016). Growing with youth: A lifewide and lifelong perspective on youth-adult partnership in youth programs. Children and Youth Services Review, 69, 248-258. https://doi.org/10.1016/j.childyouth.2016.08.019

Alexander, K. L., Entwisle, D. R., \& Olson, L. S. (2007). Lasting consequences of the summer learning gap. American Sociological Review, 72(2), 167-180. https://doi.org/10.1177/000312240707200202

Ames, C. (1992). Classrooms: Goals, structures, and student motivation. Journal of Educational Psychology, 84(3), 261-271. https://doi.org/10.1037/0022-0663.84.3.261

Bandura, A. (1991). Self-efficacy mechanism in physiological activation and health-promoting behavior. In J. Madden IV (Ed.), Neurobiology of learning, emotion, and affect (pp. 229-270). Raven Press.

Berry, T. \& LaVelle, K. B. (2013). Comparing socioemotional outcomes for early adolescents who join after school for internal or external reasons. Journal of Early Adolescence, 33(1), 77-103. https://doi.org/10.1177/0272431612466173

Blazer, C. (2011). Summer learning loss: Why its effect is strongest among low-income students and how it can be combated. https://files.eric.ed.gov/fulltext/ED536514.pdf

Burns, J. C., Cooke, D. Y., \& Schweidler, C. (2011). A short guide to community based participatory action research. Advancement Project- Healthy City Community Research Lab. https://hc-v6static.s3.amazonaws.com/media/resources/tmp/cbpar.pdf

Daly, J. (2017, August 1). Fighting lead exposure on the home front: Education, blood tests, water pipes and housing remediation. Pittsburgh Post-Gazette.

David, E. (2017, October). Food insecurity in America: Putting dignity and respect at the forefront of food aid. Social Connectedness Fellowship Program. www.socialconnectedness.org/wpcontent/uploads/2018/02/Food-Insecurity-in-America-Putting-Dignity-and-Respect-at-theForefront-of-Food-Aid.pdf 
Journal of Youth Development | http://jyd.pitt.edu/ | Vol. 16 Issue 1 DOI 10.5195/jyd.2021.1001

Internalizing Motivation

Dawes, N. P., \& Larson, R. W. (2011). How youth get engaged: Grounded-theory research on motivational development in organized youth programs. Developmental Psychology, 4 11 ), 259269. https://doi.org/10.1037/a0020729

Deci, E. L., Vallerand, R. J., Pelletier, L. G., and Ryan, R. M. (1991). Motivation and education: The selfdetermination perspective. Educational Psychologist, 26(3-4), 325-346. https://doi.org/10.1080/00461520.1991.9653137

Deci, E. L., Eghrari, H., Patrick, B. C., \& Leone, D. (1994). Facilitating internalization: The selfdetermination theory perspective. Journal of Personality, 62, 119-142.

Duerden, M. D., \& Gillard, A. (2008). Promoting supportive relationships in youth programs: A selfdetermination theory perspective. Journal of Youth Development, 3(3), 49-64. http://jyd.pitt.edu/ojs/jyd/article/view/287/273

Dweck, C. S. (1999). Essays in social psychology. Self-theories: Their role in motivation, personality, and development. Psychology Press.

Evans, G. W. (2004). The environment of childhood poverty. American Psychologist, 59(2), 77-92. http://dx.doi.org/10.1037/0003-066X.59.2.77

Ferguson, G. (2017, August 5). Be lead aware [Health education session]. Lincoln-Lemington Community Consensus Group Health Seminar, Pittsburgh, PA.

Grolnick, W. S., Farkas, M. S., Sohmer, R., Michaels, S., \& Valsiner, J. (2007). Facilitating motivation in young adolescents: Effects of an after-school program. Journal of Applied Developmental Psychology, 28, 332-344. https://doi.org/10.1016/j.appdev.2007.04.004

Hansen, D. M., \& Larson, R. W. (2007). Amplifiers of developmental and negative experiences in organized activities: Dosage, motivation, lead roles, and adult-youth ratios. Journal of Applied Developmental Psychology, 28, 360-374. https://doi.org/10.1016/j.appdev.2007.04.006

Heckman, J. J. (2007). The economics, technology, and neuroscience of human capability formation. Proceedings of the National Academy of Sciences, 104(33), pp. 13250-13255. https://doi.org/10.1073/pnas.0701362104

Hill, E., \& Sibthorp, J.. (2006). Autonomy support at diabetes camp: A self-determination theory approach to therapeutic recreation. Therapeutic Recreation Journal, 40(2), 107-125.

Holsopple, K. (2017, August 17). Teens earn and learn while educating their neighbors about lead exposure. The Allegheny Front. https://www.alleghenyfront.org/teens-earn-and-learn-whileeducating-their-neighbors-about-lead-exposure/

Hughes, K., Bellis, M. A., Hardcastle, K. A. Sethi, D., Butchart, A., Mikton, C. Jones, L., \& Dunne, M. P. (2017). The effect of multiple adverse childhood experiences on health: A systematic review and meta-analysis. The Lancet: Public Health, 2(8), E356-E366. https://doi.org/10.1016/S24682667(17)30118-4 
Journal of Youth Development ｜ http://jyd.pitt.edu/ | Vol. 16 Issue 1 DOI 10.5195/jyd.2021.1001

Internalizing Motivation

Jones, D. L. (2017). Saying yes to Y.E.S.: A qualitative analysis of the factors that attract and sustain lowincome students' participation in summer learning programs [Unpublished master's thesis]. Columbia University.

Jones, D. L., Darsow, E., \& Jones, D. F. (2020). Preliminary testing of a peer-teaching model utilizing geospatial open source tools to address community health issues. Journal of STEM Outreach, 3(1), 1-7. https://doi.org/10.15695/istem/v3i1.11

Jones, D. L., \& Jones, D. F. (2018). Youth Enrichment Services summer report. https://docs.wixstatic.com/ugd/930de5 82b7c9c2f5f54ec0947858e7fff9e7fc.pdf

Jones, D., \& Jones, D. (2020). Transcend the summer slump: How to attract and retain low-income high school students in summer learning programs. Afterschool Matters Journal, Spring 2020. https://files.eric.ed.gov/fulltext/EJ1249563.pdf

Jones, D. L., \& Jones, D. F. (2021). Growth through the decade: 2010-2020 (YES snapshot report). https://61e6abc2-c304-49a1-ab51b9d904a42732.filesusr.com/ugd/930de5 65992f13ddd24cdb82ad1531aa0b460d.pdf

Joseph, S. (2012, October 7). Unconditional positive regard. Psychology Today. www.psychologytoday.com/us/blog/what-doesnt-kill-us/201210/unconditional-positive-regard

Larson, R. (2011). Positive development in a disorderly world. Journal of Research on Adolescence, 21(2), 317-334. https://doi.org/10.1111/j.1532-7795.2010.00707.x

Larson, R. W., \& Rusk, N. (2011). Intrinsic motivation and positive development. In R. M. Lerner, J. V. Lerner, \& J. B. Benson (Eds.), Advances in child development and behavior (Vol. 41, pp. 89-130). Academic Press.

Lave, J., \& Wenger, E. (1991). Situated learning: Legitimate peripheral participation. Cambridge University Press.

Maehr, M. L., \& Midgley, C. (1991). Enhancing student motivation: A schoolwide approach. Educational Psychologist, 26, 399-427. https://doi.org/10.1080/00461520.1991.9653140

Martin, A. J. (2005). Exploring the effects of a youth enrichment program on academic motivation and engagement. Social Psychology of Education, 8, 179-206. https://doi.org/10.1007/s11218-004$\underline{6487-0}$

Maslow, A. H. (1970). Motivation and personality. Harper \& Row.

Morton, M., \& Montgomery, P. (2013). Youth empowerment programs for improving self-efficacy and self-esteem of adolescents. Research on Social Work Practice, 23(1), 22-33. https://doi.org/10.1177/1049731512459967

Mullainathan, S., \& Shafir, E. (2014). Scarcity: The new science of having less and how it defines our lives. Picador. 
Journal of Youth Development ｜ http://jyd.pitt.edu/ | Vol. 16 Issue 1 DOI 10.5195/jyd.2021.1001

Internalizing Motivation

Murphy, K. P., \& Alexander, P. A. (2000). A motivated exploration of motivation terminology. Contemporary Educational Psychology, 25, 3-53. https://doi.org/10.1006/ceps.1999.1019

Newton, M., Watson, D. L., Kim, M. S., \& Beacham, A. O. (2006). Understanding motivation of underserved youth in physical education settings. Youth \& Society, 37(3), 348-371. https://doi.org/10.1177/0044118X05278964

Noguera, P. (2008). The trouble with black boys: And other reflections on race, equity, and the future of public education. Jossey-Bass.

Partner4Work. (n.d.). Learn \& earn. https://www.partner4work.org/learnandearn

Pintrich, P. R. (2000). Multiple goals, multiple pathways: The role of goal orientation in learning and achievement. Journal of Educational Psychology, 92(3), 544-555. https://doi.org/10.1037/0022$\underline{0663.92 .3 .544}$

Poindexter, M. (2017). Lead (Pb) project summary and report. Unpublished manuscript.

Reed, A. (2019, March 14). From mentee to mentor: Moving through the stages of wise mentorship. Conference on College Composition and Communication. Pittsburgh, PA.

Reeve, J., Ryan, R., Deci, E. L., \& Jang, H. (2008). Understanding and promoting autonomous selfregulation: A self-determination theory perspective. In D. H. Schunk \& B. J. Zimmerman (Eds.), Motivation and self-regulated learning: Theory, research, and applications (pp. 223-244), Lawrence Erlbaum Associates.

Rogers, C. R. (1957). The necessary and sufficient conditions of therapeutic personality change. Journal of Consulting Psychology, 21(2), 95-103. https://doi.org/10.1037/h0045357

Ryan, R. M. (1982). Control and information in the intrapersonal sphere: An extension of cognitive evaluation theory. Journal of Personality and Social Psychology, 43, 450-461.

Ryan, R. M., Connell, J. P., \& Plant, R. W. (1990). Emotions in non-directed text learning. Learning and Individual Differences, 2, 1-17.

Ryan, R. M., \& Deci, E. L. (2000). Self-determination theory and the facilitation of intrinsic motivation, social development, and well-being. American Psychologist, 55(1), 68-78. selfdeterminationtheory.org/SDT/documents/2000_RyanDeci_SDT.pdf

Safavian, N. (2019). What makes them persist? Expectancy-value beliefs and the math participation, performance, and preparedeness of Hispanic youth. AERA Open, 5(3), 1-17. https://doi.org/10.1177/2332858419869342

Sapolsky, R. M. (1994). Why zebras don't get ulcers: A guide to stress, stress-related diseases, and coping. W. H. Freeman and Company.

Schrobsdorff, S. (2016, October 27). Teen depression and anxiety: Why the kids are not all right. Time. http://time.com/magazine/us/4547305/november-7th-2016-vol-188-no-19-u-s/ 
Journal of Youth Development ｜ http://jyd.pitt.edu/ | Vol. 16 Issue 1 DOI 10.5195/jyd.2021.1001

Internalizing Motivation

Schunk, D. H. (1991). Self-efficacy and academic motivation. Educational Psychologist, 26(3/4), 207-231. https://doi.org/10.1080/00461520.1991.9653133

Schunk, D. H. (2000). Coming to terms with motivation constructs. Contemporary Educational Psychology, 25, 16-119, https://doi.org/10.1006/ceps.1999.1018

Schwartz, B. (2015). Why we work. Simon \& Schuster.

Skinner, B. F. (1953). Science and human behavior. Macmillan.

Standage, M., Duda, J. L., \& Ntoumanis, N. (2006). Students' motivational processes and their relationship to teacher ratings in school physical education: A self-determination theory approach. Research Quarterly for Exercise and Sport, 771), 100-110. https://doi.org/10.1080/02701367.2006.10599336

Sum, A., Khatiwada, I., Trubskyy, M., Ross, M., McHugh, W., \& Palma, S. (2014, March). The plummeting labor market fortunes of teens and young adults. https://www.brookings.edu/wpcontent/uploads/2014/03/Youth Workforce Report FINAL.pdf

Thompson, D. (2015, July/August). A world without work. Atlantic Magazine. www.theatlantic.com/magazine/archive/2015/07/world-without-work/395294/

Tough, P. (2012). How children succeed: Grit, curiosity, and the hidden power of character. Houghton Mifflin Harcourt.

Tough, P. (2016). Helping children succeed: What works and why. Houghton Mifflin Harcourt.

van Egmond, M. C., Hanke, K., Omarshah, T. T., Berges, A. N., Zango, V., \& Sieu, C. (2020). Self-esteem, motivation and school attendance among sub-Saharan African girls: A self-determination theory perspective. International Journal of Psychology, 55(5), 842-850.

https://doi.org/10.1002/ijop.12651

Weiner, B. (1985). An attributional theory of achievement motivation and emotion. Psychological Review, 92(4), 548-573. https://doi.org/10.1037/0033-295X.92.4.548

Wigfield, A. (1994). Expectancy-value theory of achievement motivation: A developmental perspective. Educational Psychology Review, 6, 49-78. https://doi.org/10.1007/BF02209024

Wigfield, A., \& Eccles, J. S. (2000). Expectancy-value theory of achievement motivation. Contemporary Educational Psychology, 25, 68-81. https://doi.org/10.1006/ceps.1999.1015

Yeager, D. S., Henderson, M. D., Panuesku, D., Walton, G. M., D’Mello, S., Spitzer, B. J., \& Duckworth, A. L. (2014). Boring but important: A self-transcendent purpose for learning fosters academic selfregulation. Journal of Personality and Social Psychology, 1074), 559-580.

http://dx.doi.org/10.1037/a0037637

Yeager, D. S., Purdie-Vaughns, V., Garcia, J., Apfel, N., Brzustoski, P., Master, A., Hessert, W. T., Williams, M. E., \& Cohen, G. L. (2014). Breaking the cycle of mistrust: Wise interventions to 
Journal of Youth Development | http://jyd.pitt.edu/ | Vol. 16 Issue 1 DOI 10.5195/jyd.2021.1001

Internalizing Motivation

provide critical feedback across the racial divide. Journal of Experimental Psychology, 143(2), 804-824. http://dx.doi.org/10.1037/a0033906

Youth Engagement Services. (n.d.). Our story. https://www.youthenrichmentservices.org/

Zimmerman, B. J. (2000). Self-efficacy: An essential motive to learn. Contemporary Educational Psychology, 25, 82-91. https://doi.org/10.1006/ceps.1999.1016

Zimmerman, B. J., \& Schunk, D. H. (2008). Motivation: An essential dimension of self-regulated learning. In D. H. Schunk \& B. J. Zimmerman (Eds.), Motivation and self-regulated learning: Theory, research, and applications (pp. 1-30). Lawrence Erlbaum Associates. 